\title{
بعث بعنوان
}

قياس كفاءة الآداء المالى فى شركات التأمين على الحياة التجارى باستخدام

\section{السلاسل الزمنية المقطعية (Panel Data)}

مستخلص من رسالة دكتوراه بعنوان

(قياس الكفاءة المالية فى شركات التأمين على الحياة - دراسة مقارنة بين شركات

التأمين التجارى والتكافلى فى السوق المصرى)

$$
\text { إعداد }
$$

الأميرة سرور سعد عثمان(1)

مدرس مساعد بقسم الرياضيات والإحصاء

كلية إدارة الأعمال

جامعة النهضة إلها الاعمال

\section{تحت إثراف}

الاكتور/ محمد محمد السيد حافظ

مدرس بقسم الرياضة والتأمين

كلية التجارة - جامعة بنى سويف لتصني ولتمين
الأستاذ الاكتور/ عيد أحمد أبو بكر أستاذ التأمين بقسم الرياضة وإلتأمين كلية التجارة - جامعة بنى سويف ووكيل الكلية لشئون التعليم والطلاب

الملخص:

تهذف الدراسة إلى التعرف على العومل التى تئثر على كفاءة الآداء المالى فى شركات

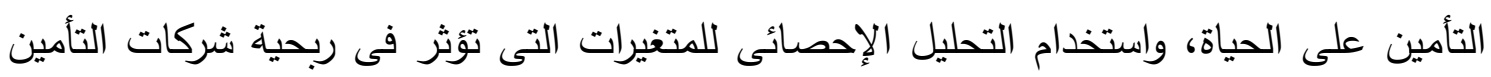

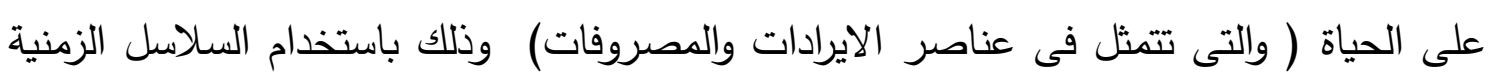

1 Alamira.sroor@nub.edu.eg

Drelamira25@gmail.com 
المقطعية وذلك لعدد 10 شركات تأمين على الحياة خلال الفترة من 2011/2010 حتى 2019/2018. وتوصلت الدراسة إلى وجود متغيرين مستقلين من ضمن سبعة متغيرات هما اللذان

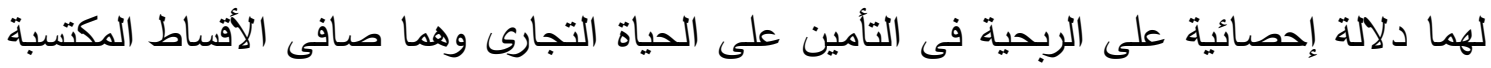
وصافى الدخل من الاستثمار • وتوصى الدراسة بضرورة استحداث نماذج كمية لقياس كفاءة الآداء

$$
\text { المالى فى شركات التأمين على الحياة. }
$$

الكلمات المفتاحية: التأمين على الحياة, الكفاءة المالية، الربحية، عناصر الإيرادات والمصروفات،

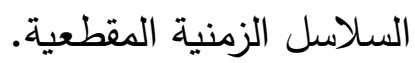

\section{Abstract}

The study aims to identify the factors that affect the efficiency of financial performance in Life insurance companies using statistical analysis of the variables that affect the profitability of life insurance companies, using the time series method (Panel data), on ten life insurance companies during the period from 2010/2011 until 2018/2019. The study indicated that there are two independent variables out of seven variables that have a statistical significance of profitability in commercial life insurance, namely earned premiums and net income from investment. The study recommends the need to develop quantitative models to measure the efficiency of financial performance in life insurance companies.

Key words: Life insurance, financial efficiency, Profitability, expenses and revenues elements, Panel Data.

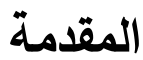

يحتل قطاع التأمين موقعاً استراتيجياً بين القطاعات الاقتصادية الأخرى ، حيث أنه يوفر

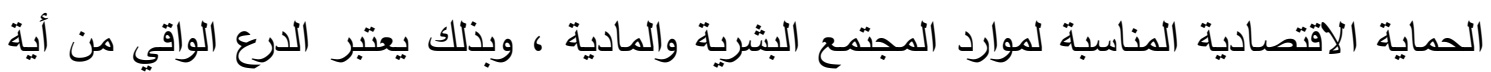

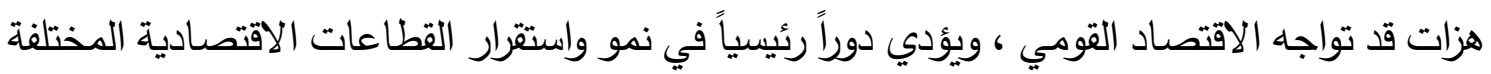

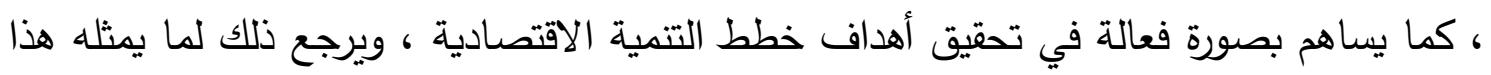
القطاع من ثقل مالي نتيجة للدور البارز الذي تقوم به شركات التهات التأمين في تجميع المدخرات الوطنية مما يتطلب من هذه الثركات درجة عالية من الكفاءة المالية ، ويلقي العبء والمسئولية على هيئة

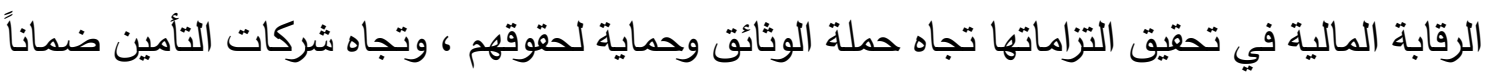

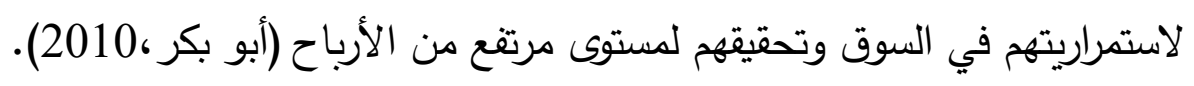


وتقوم شركات التأمين التجارى فى مقابل تقديم الخدمة التأمينية لطالبها بتحصيل الأقساط منهم مقدماً, وتستخدم هذه الأقساط المحصلة مقدما فى الوفاء بالتزامات شركة التأمين فى مواعيد

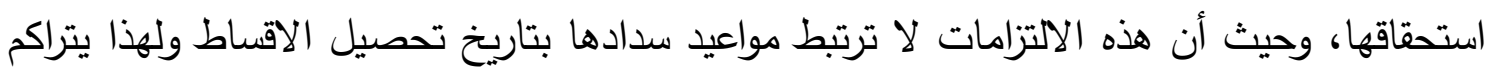

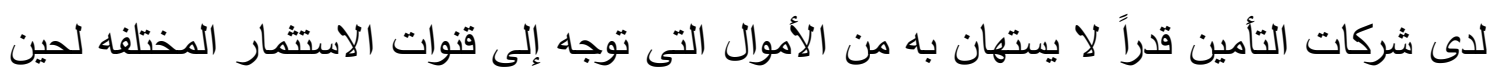

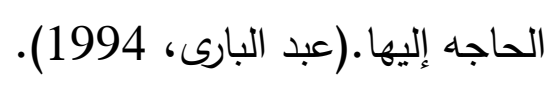

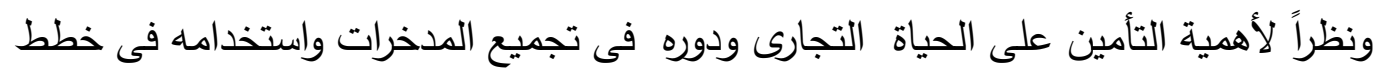

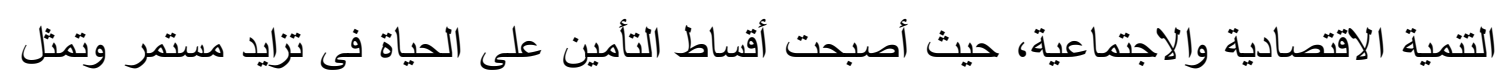

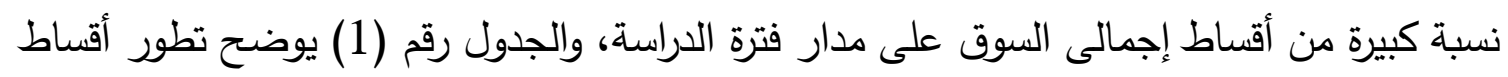

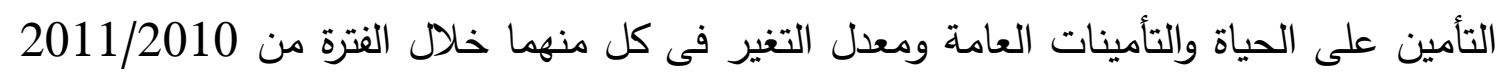
حتى 2019/2018.

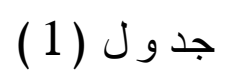

تطور الأقساط المباشرة لتأمينات الحياة ولتأمينات الممتلكات والمسؤلية ولإجمالى السوق ككل

\begin{tabular}{|c|c|c|c|c|c|c|c|c|c|}
\hline \multirow{4}{*}{ نسبة (1)/(3) } & \multicolumn{2}{|c|}{ إجمالى السوق } & \multicolumn{3}{|c|}{ تأمينات الممتلكات والمسؤلية } & \multicolumn{3}{|c|}{ تأمينات الحياة } & \multirow{4}{*}{ / السنة } \\
\hline & معدل & القيمة & الرقم & معدل & القيمة & الرقم ل & معدل & القيمة & \\
\hline & التغير & (3) & القياسى & التغير & (2) & القياسى & التغير & (1) & \\
\hline & السنوى & & & السنوى & & & السنوى & & \\
\hline 41 & 9.9 & 9655149 & 100 & 9.3 & 5655426 & 100 & 10.9 & 3999723 & $2010 / 2011$ \\
\hline 42 & 9.5 & 10571964 & 108 & 8 & 6088898 & 112 & 12 & 4483066 & $2011 / 2012$ \\
\hline 43 & 15.6 & 12220837 & 123 & 14 & 6953525 & 132 & 17 & 5267312 & $2012 / 2013$ \\
\hline 45 & 12.1 & 13701267 & 133 & 9 & 7846710 & 154 & 17 & 6154558 & $2013 / 2014$ \\
\hline 47 & 12.8 & 15457311 & 144 & 8 & 8117980 & 183 & 19 & 7339332 & $2014 / 2015$ \\
\hline 48 & 12.1 & 17334241 & 159 & 11 & 9009391 & 208 & 13 & 8324850 & $2015 / 2016$ \\
\hline 45 & 29.7 & 22474218 & 218 & 37 & 12328621 & 254 & 22 & 10145598 & $2016 / 2017$ \\
\hline 44 & 23.4 & 27742635 & 276 & 27 & 15621435 & 303 & 19 & 12121200 & $2017 / 2018$ \\
\hline 46 & 20.5 & 33420411 & 320 & 16 & 18112579 & 383 & 26 & 15307832 & $2018 / 2019$ \\
\hline
\end{tabular}
خلال الفترة من 2011/2010 حتى 2019/2018

المصدر : الكتاب الإحصائى السنوى عن نشاط سوق التأمين فى مصر ، هيئة الرقابة المالية، أعداد مختلفة 
يتضح من الجدول السابق أن أقساط تأمينات الحياة تمثل حوالى 45\% من إجمالى أقساط

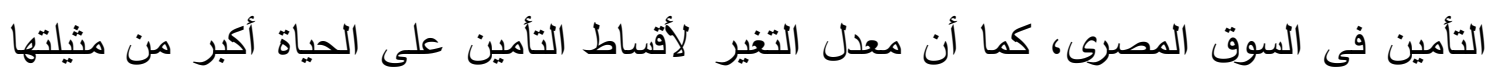

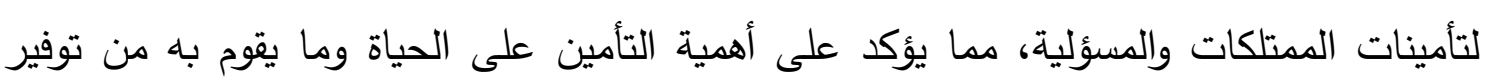

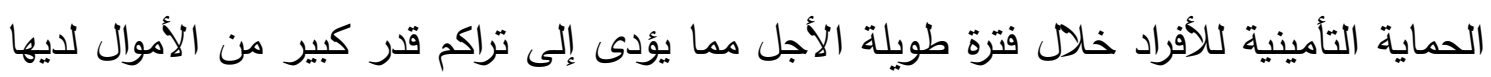

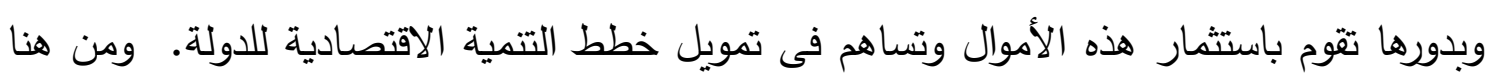
يتضح أهمية قياس الكفاءة المالية لثركات التأمين على الحياة. مشكلة الاراسة الهية

نلاحظ أنه فى الآونة الأخيرة تزايد عدد شركات التأمين التجارى التى تمارس تأمينات الحياة

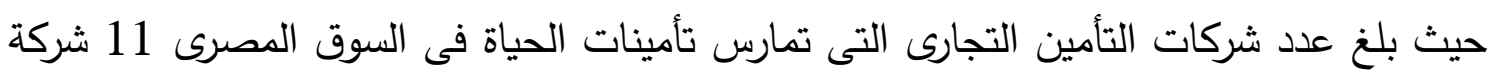

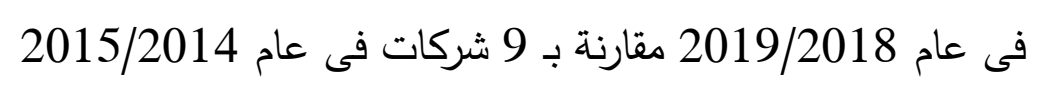

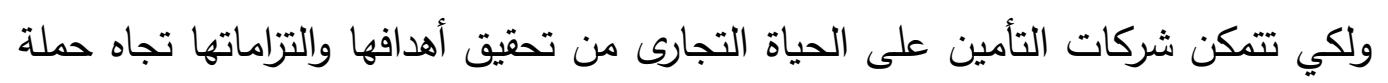

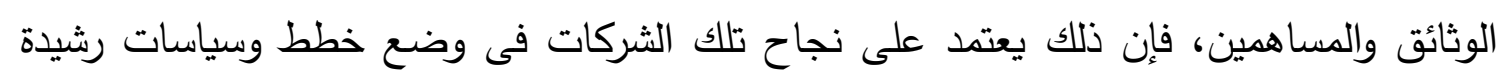

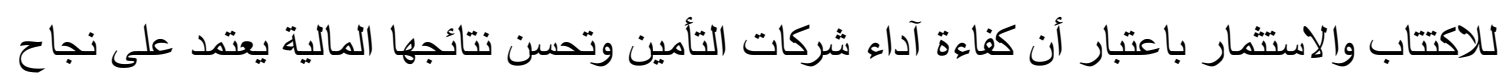

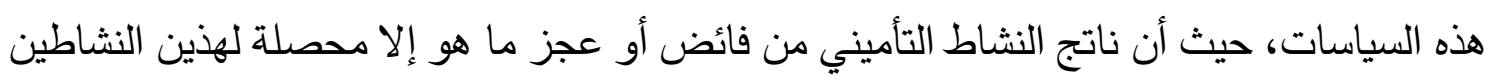

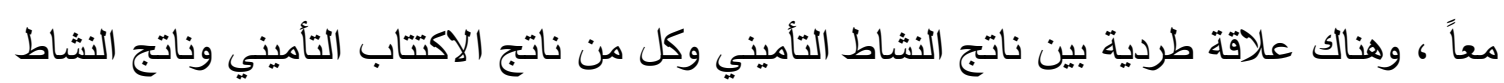

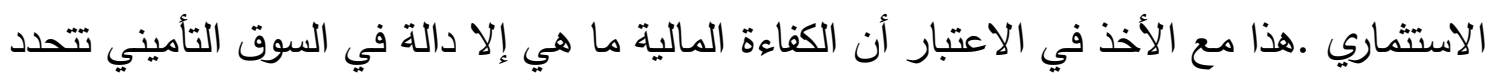
في ضوء متغيرات وعوامل متعددة.(أبو بكر، ،2006). وبفحص ناتج (فائض أو عجز) النشاط التأمينى فى شركات التأمين على الحياة التجارى

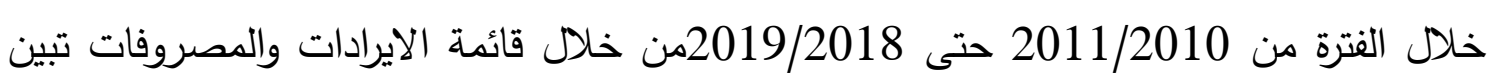

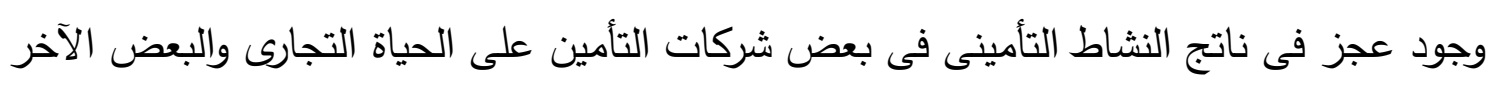

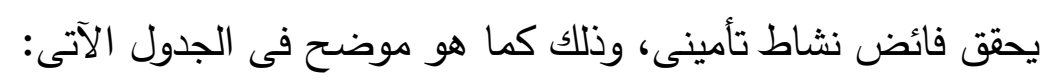


الأميرة سرور سعد قياس كفاءة الداء المالي في شركات التأمين على الحياة

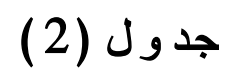

تطور ناتج (فائض أو عجز) النشاط التأمينى فى شركات التأمين على الحياة التجارى خلال الفترة من 2011/2011/2010 حتى 2019/2018

\begin{tabular}{|c|c|c|c|c|c|c|c|c|c|c|}
\hline $2019 / 2018$ & 2018/2017 & $2017 / 2016$ & $2016 / 2015$ & $2015 / 2014$ & $2014 / 2013$ & $2013 / 2012$ & $2012 / 2011$ & $2011 / 2010$ & \multirow{3}{*}{\multicolumn{2}{|c|}{ 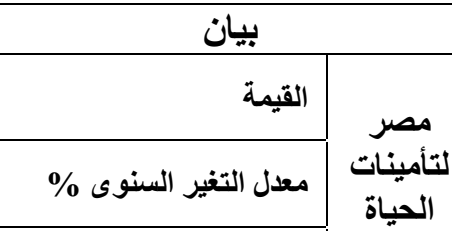 }} \\
\hline 796966 & 706666 & 829285 & 255530 & 212464 & 983332 & 35048 & 80205 & 121862- & & \\
\hline 13 & $15-$ & 225 & 20 & 78- & 2706 & $56-$ & 166- & & & \\
\hline 654- & $580-$ & 681- & $210-$ & 174- & 807- & $29-$ & $66-$ & 100 & الرقم القياسى \% & \\
\hline 87734 & 72088 & 64590 & 29814 & 19780 & 5026 & 5107 & 2781 & 1298 & القيمة & \multirow{3}{*}{ 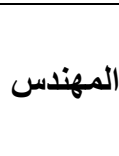 } \\
\hline 22 & 12 & 117 & 51 & 294 & 2- & 84 & 114 & & معدل التغير السنوى \% & \\
\hline 6759 & 5554 & 4976 & 2297 & 1524 & \%387 & \%393 & 214 & 100 & الرقم القياسى \% & \\
\hline 41622 & 38165 & 36328 & 15868 & 14464 & 11292 & 10868 & 6149 & 1167 & القيمة & \multirow{3}{*}{ الدلتا الدا } \\
\hline 9 & 5 & 129 & 10 & 28 & $\% 4$ & $\% 77$ & $\% 427$ & & معدل التغير السنوى \% & \\
\hline 3567 & 3270 & 3113 & 1360 & 1239 & $\% 968$ & $\% 931$ & $\% 527$ & 100 & الرقم القياسى \% & \\
\hline 64316 & 33073 & 18459 & 15568 & 6725 & 2299 & 714 & OYVY- & 1274 & القيمة & \multirow{3}{*}{ السويس } \\
\hline 94 & 79 & 19 & 131 & 193 & $\% 222$ & $\% 114$ & $\% 514-$ & & معدل التغير السنوى \% & \\
\hline 5048 & 2596 & 1449 & 1222 & 528 & $\% 180$ & $\% 56$ & \%414- & 100 & الرقم القياسى \% & \\
\hline 321413 & 359350 & 373872 & 199703 & 167505 & 42168- & 37509 & 47948 & 75522 & القيمة & \multirow{3}{*}{ التأميناتي } \\
\hline 11- & 4- & 87 & 19 & 497- & 212- & $22-$ & 37- & & معدل التغير السنوى \% & \\
\hline 426 & 476 & 495 & 264 & 222 & $56-$ & 50 & 63 & 100 & الرقم القياسى \% & \\
\hline
\end{tabular}


الأميرة سرور سعد قياس كفاءة الداء المالي في شركات التأمين على الحياة

تابع جدول (2)

\begin{tabular}{|c|c|c|c|c|c|c|c|c|c|c|}
\hline 147834 & 145545 & 109618 & 74949 & 51261 & 67071 & 58211 & 60216 & 55868 & القيمة & \multirow{3}{*}{ تلتميناة } \\
\hline$\% 2$ & $\% 33$ & $\% 46$ & $\% 46$ & $\% 24-$ & $\% 15$ & $\% 3-$ & $\% 8$ & & \% معل التغير السنوى & \\
\hline$\% 265$ & $\% 261$ & $\% 196$ & $\% 134$ & $\% 92$ & $\% 120$ & $\% 104$ & $\% 108$ & $\% 100$ & الرقم القياسى \% & \\
\hline 78240 & 104011 & 66485 & 46185 & 100697 & 62037 & 34328 & 9994 & 11831 & القيمة & \multirow{3}{*}{ كلتأمين } \\
\hline$\% 25-$ & $\% 56$ & $\% 44$ & $\% 54-$ & $\% 62$ & $\% 81$ & $\% 243$ & $\% 16-$ & & \% معل التغير السنوى & \\
\hline$\% 661$ & $\% 879$ & $\% 562$ & $\% 390$ & $\% 851$ & $\% 524$ & $\% 290$ & $\% 84$ & $\% 100$ & الرقم القياسى \% & \\
\hline 17694 & 11895 & 5341 & 981 & 1301 & 10771- & 14677 & 17066- & 一 & القيمة & \multirow{3}{*}{ 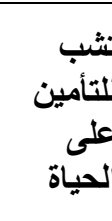 } \\
\hline$\% 49$ & $\% 123$ & $\% 444$ & $\% 25-$ & \%112- & $\% 173-$ & $\% 186-$ & & & \% معل التغير السنوى & \\
\hline \%104- & $\% 70-$ & \%31- & \%6- & $\% 8$ & $\% 63$ & \%86- & $\% 100$ & & الرقم القياسى \% & \\
\hline 120811 & 100493 & 66221 & 52484 & 49804 & 42750 & 22268 & 25554 & 16612 & القيمة & \multirow{3}{*}{ 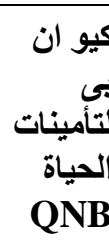 } \\
\hline$\% 20$ & $\% 52$ & $\% 26$ & $\% 5$ & $\% 17$ & $\% 92$ & $\% 13-$ & $\% 54$ & & \% معل التغير السنوى & \\
\hline$\% 727$ & $\% 605$ & $\% 399$ & $\% 316$ & $\% 300$ & $\% 257$ & $\% 134$ & $\% 154$ & $\% 100$ & الرقم القياسى \% & \\
\hline 4567 & 2781 & 1680- & 4993- & 3611- & $6437-$ & 4015- & 4704- & 4041- & القيمة & \multirow{3}{*}{ اللتامئن } \\
\hline$\% 64$ & $\% 266-$ & $\% 66-$ & $\% 38$ & $\% 44-$ & $\% 60$ & $\% 15-$ & $\% 16$ & & \% معل التغير السنوى & \\
\hline \%113- & $\% 69-$ & $\% 42$ & $\% 124$ & $\% 89$ & $\% 159$ & $\% 99$ & $\% 116$ & $\% 100$ & الرقم القياسى \% & \\
\hline
\end{tabular}

الدصدر: إعداد الباحث من واقع الكتاب الإحصائى السنوى عن نثاط سوق التأمين فى مصر ، هيئة الرقابة المالية، أعداد مختلفة 
يتضح من الجدول السابق وجود عجز فى ناتج النشاط التأمينى فى شركات التأمين على الحياة التجارى للعديد من الثركات، مما يتطلب معه دراسة العوامل التى تئثر فى ناتج النشاط

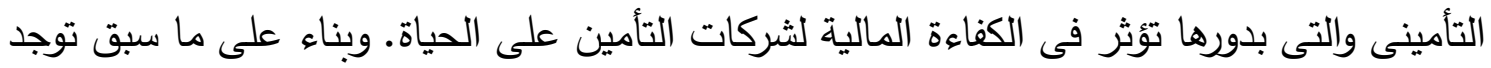
ضرورة لقياس كفاءة الآداء المالى فى شركات التأمين على الحياة التجارى، وهذا يتطلب استخدام

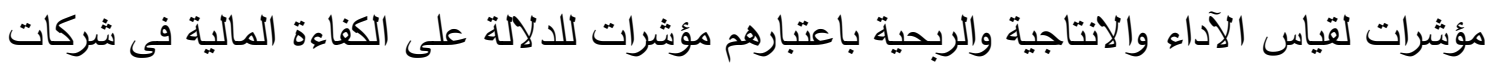
التأمين على الحياة التجارى. هدف الاراسة

تهدف الدراسة إلى اقتراح نموذج كمي يستخدم في قياس وتحديد المحددات المؤثرة على المى

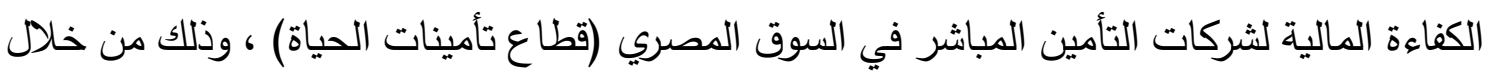
التحقق من مدى الكفاءة المالية لشركات التأمين (قطاع التأمين على الحياة) على الوفاء بالتزاماتها تجاه المؤمن عليهخ بالإضافة إلى تحديد أهم المتغيرات المؤثرة على مستوى الكفاءة المالية. أهمية الدراسة تتبع أهمية الدراسة من الآتى: الاسه

1) العود العديد من المتغيرات المؤثرة فى الكفاءة المالية فى شركات التأمين على الحياة.

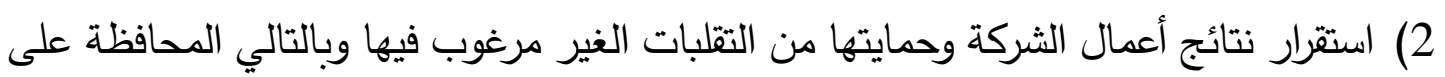

هامش الملاءة المالية Solvency margin. 3) إمكانية تقييم الأداء المالي لشركات التأمين. 4) ضمان استمرارية السيولة النقدية بالثركة.أن ربحية شركات التأمين المباشر تعتد بدرجة الثبات كبيرة على حسن سياستها المالية والاستثمارية 5) دراسة العوامل المؤثرة في الآداء المالي لثركات التأمين باتت ضرورة بحثية يمكن من خلالها التحقق من الدور الذي من المكن أن تلعبه هذا العوامل في الآداء المالي. فروض الدراسة

يمكن تحديد فروض الدراسة في ضوء العلاقة بين خصائص سوق تأمينات الحياة المصري

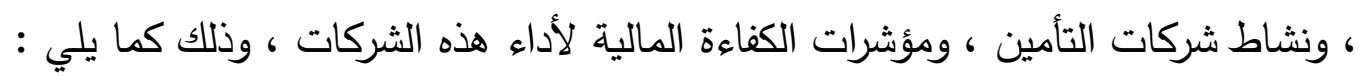

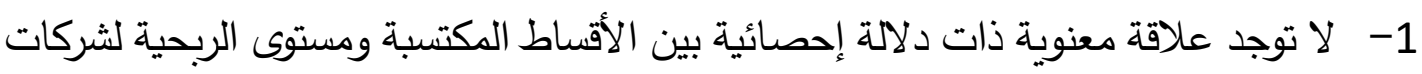

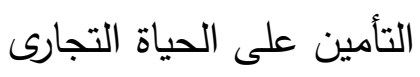


2- لا توجد علاقة معنوية ذات دلالة إحصائية بين عمولات إعادة التأمين الصادر ومستوى الربحية لشركات التأمين على الحياة التجارى. 3- لا توجد علاقة معنوية ذات دلالة إحصائية بين صافي الدخل من الاستثمارات ومستوى لألئ الربحية لشركات التأمين على الحياة التجارى.

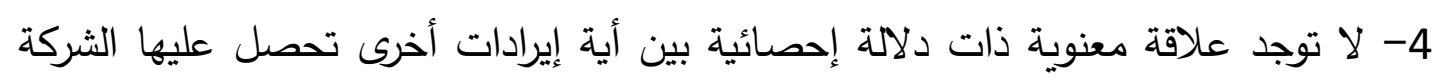
ومستوى الربحية لشركات التأمين على الحياة التجارى.

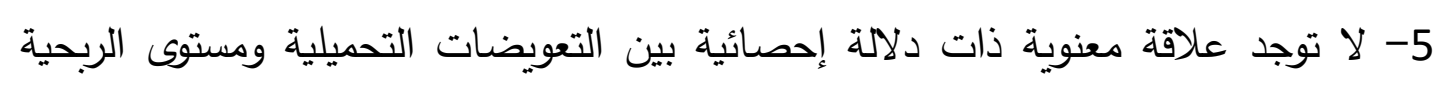
لشركات التأمين على الحياة التجارى. 6- لا توجد علاقة معنوية ذات دلالة إحصائية بين العمولات وتكاليف الإنتاج ومستوى الربحية لشركات التأمين على الحياة التجارى. 7- لا توجد علاقة معنوية ذات دلالة إحصائية بين المصروفات الإدارية والعمومية ومستوى الحئ الربحية لشركات التأمين على الحياة التجارى. تقتصر الدراسة على : 1) شركات التأمين على الحياة التجارى فى السوق المصرى وعددهم عشر شركات وهم شركة

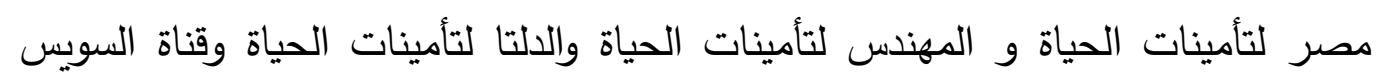
لتأمينات الحياة واليانز لتأمينات الحياة وميتلايف وأكسا وتثب وكيو انى بى واروب لتأمينات

$$
\begin{aligned}
& \text { الحياة } \\
& \text { 2) الفترة من 2011/2010 حتى 2019/2018. } \\
& \text { منهج الدراسة }
\end{aligned}
$$

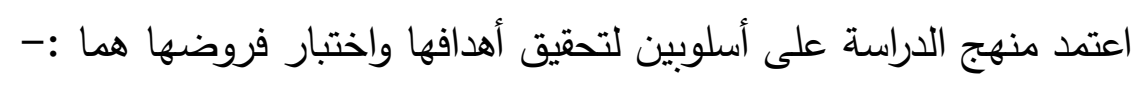

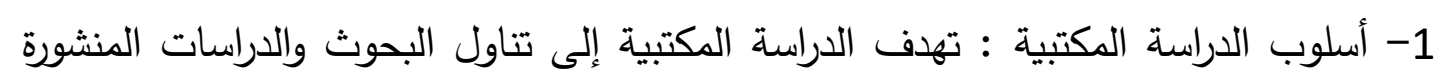

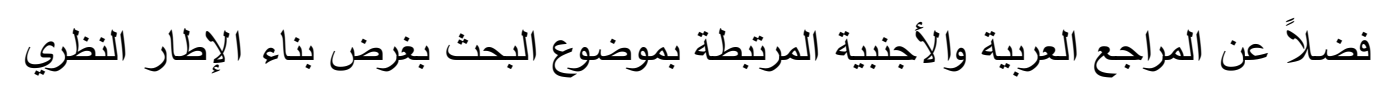
للدراسة. 2- أسلوب الدراسة التطبيقية : وذلك بالتحليل الإحصائي للعوامل المؤثرة على الآداء المالى في

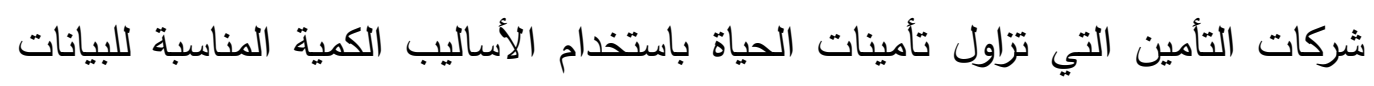


المنشورة في الكتاب الإحصائي السنوي الذي تصدره هيئة الرقابة المالية عن نشاط سوق التامين فى مصر التأمين والتي على أساس بياناتها تم تحديد النموذج الكمي المقترح.

\section{الادراسات السابقة \\ 1) دراسة (عفاف البحبوحى، 2001)}

وقد تتاولت الدراسة تقييم أعمال شركات التأمين فرع الحياة فى السوق المصرى وذلك من

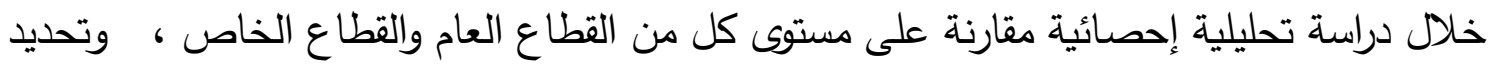

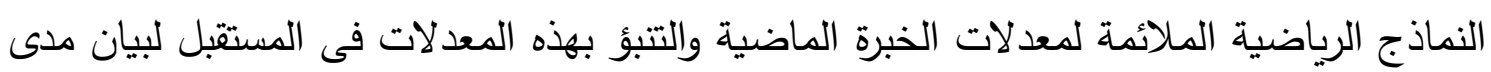

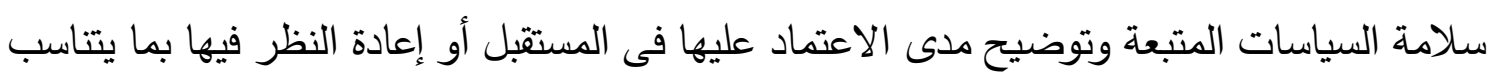
مع مصلحة سوق التأمين عامة

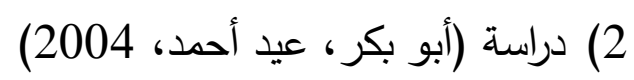
هدفت هذه الدراسة إلى تقديم دراسة تحليلية إحصائية لمعدلات تحميلات قسط التأمين فى تأمينات الحياة بالسوق المصرى وذلك على مستوى كل شركة من شركات التأمين وعلى مستوى دلى دلى

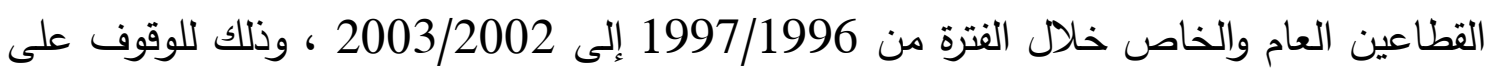
مدى كفاءة كل شركة وقدرتها على تقديم الخدمة التأمينية بأقل تكلفة مدكنة ومحاولة ترشيد تلك الك الكالك

$$
\begin{aligned}
& \text { التحميلات على القسط الصافى. } \\
& \text { 3) دراسة (أبو بكر، عيد أحمد ، 2006) }
\end{aligned}
$$

هدفت هذه الدراسة إلى دراسة العوامل المؤثرة على الكفاءة المالية فى التأمين على الحياة

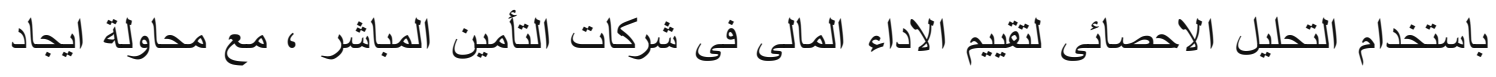

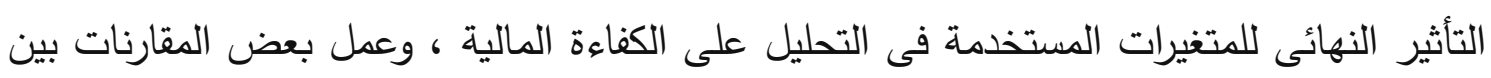
شركات التأمين القطاع العام وشركات التأمين القطاع الخاص. 4) دراسة (جلول، 2007)

هدفت هذه الدراسة إلى تقييم العوامل والمتغيرات الداخله فى حساب تكلفة تأمينات الحياة فى هي السوق المصرية بهف ترشيدها والوصول بها إلى أدنى ما يمكن، كما هدفت الدراسة إلى تقييم أعمال

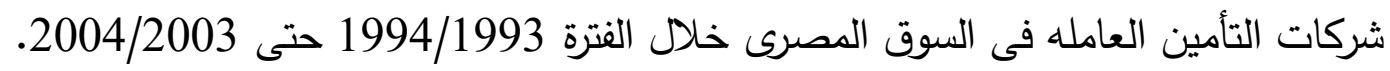

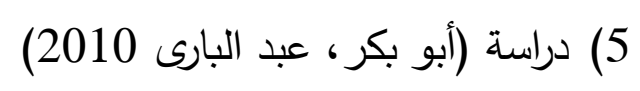


هدفت هذه الدراسة إلى فحص العلاقة بين ناتج ( فائض أو عجز ) النشاط التأمينى فى

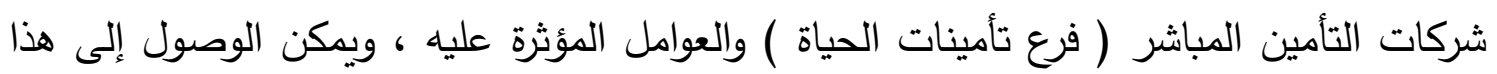

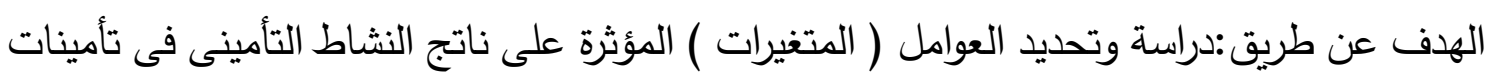
الحياة بشركات التأمين المباشر بالسوق المصرى وبيان علاقة كل متغير من هذه المتغيرات بناتج النشاط التأمينى سواء كانت طردية أو عكسية.

$$
\text { 6) دراسة (أبو بكر 2013) }
$$

هدفت الدراسة إلى تقييم الاداء المالى لثركات التأمين المباشر في السوق المصري (قطاع

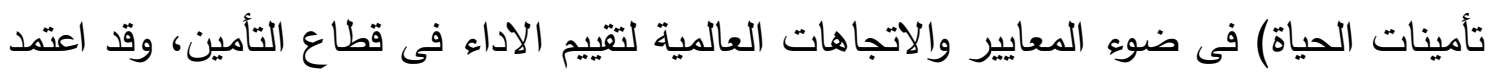

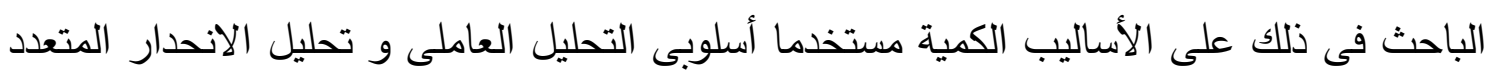

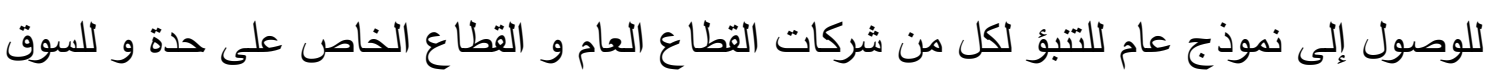
ككل.

\section{ثانيا الدراسات الأجنبية}

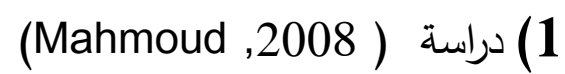

هدفت هذه الدراسة إلى استخدام البيانات المالية لبعض شركات تأمينات الممتلكات والمسؤلية

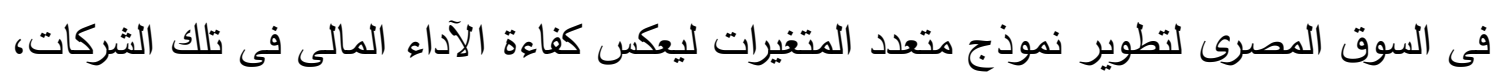
حيث تم تصنيف البيانات إحصائيا بين ثلاث مجموعات من الآداء المالى بناء على نتائج التحليل العنقودى، وتم تمثيل المتغيرات التتبؤية للنموذج متعدد المتغيرات فى شكل 25 نسبة مالية يتم التئ

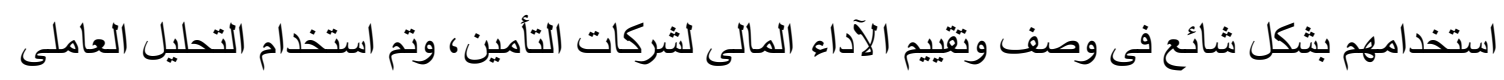
لتخفيض عدد المتغيرات، وتم استخدام اسلوبى تحليل التمايز والانحدار اللوجستى. 2) دراسة (Almajali et al.,2012) هدفت هذه الدراسة إلى دراسة العوامل التى تؤثر على الآداء المالى لشركات التأمين

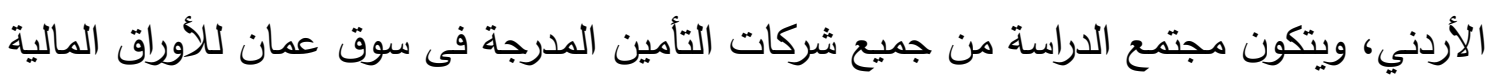

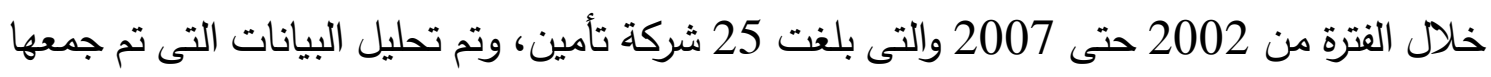

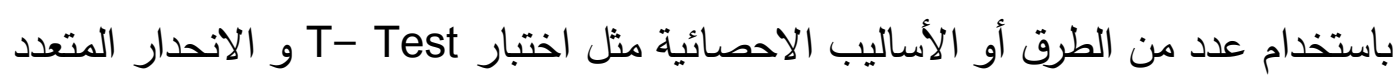
(3) دراسة (Akotey et al.,2013) 
هدفت هذه الدراسة إلى تتييم الآداء المالى لصناعة التأمين على الحياة ودراسة المحددات

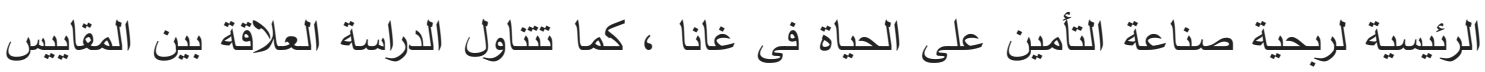

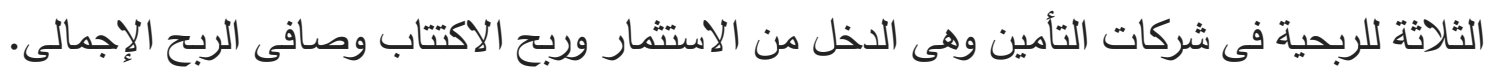
حيث تم أخذ عينة مكونة من عشر شركات تأمين على الحياة خلال 11 عام وتحليلها باستخدام

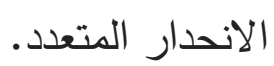

4) دراسة (Derbali and Jamel, 2018)

هدفت الدراسة إلى تحديد تأثير الخصائص الخاصة بشركة التأمين وهى (الحجم والرافعة المالية والمخاطر والنمو والسيولة وعمر الشركة على ربحية 8 شركات تأمين تونسية خلال الفترة من

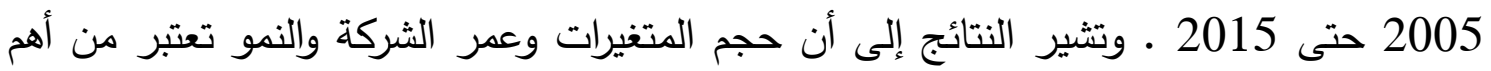

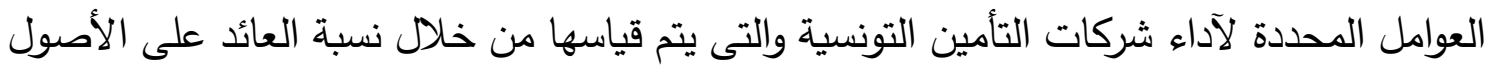
وأن الرافعة المالية والسيولة والمخاطر لا تؤثر على آداء شركات التأمين التونسية.

قياس الكفاءة المالية فى شركات التامين على العياة التجارى باستخدام السلاسل الزمنية المقطعية تعتبر الكفاءة أهم التحديات التى تواجه شـــركات التأمين حتى يمكنها مواكبة التطورات

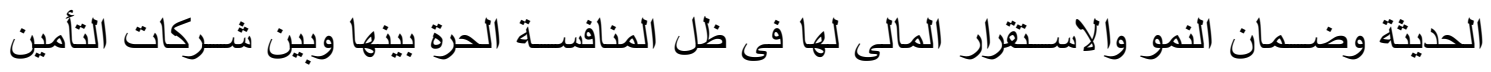
الأجنبية. ولذلك تهدف الدراســـة إلى اقتراح نموذج كمى لتحديد أهم العوامل المحددة للكفاءة المالية لآداء شركات التأمين وكذلك استخدام اسلوب تحليل السلاسل الزمنية المتقطعة لاختيار المتغيرات

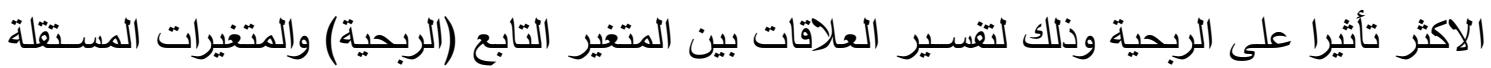
(عناصر الايرادات والمصروفات) ونتناول النموذج الكمى المقترح من خلال المحاور الآتيه:

أولاً مفهوم نماذج السلاسل الزمنية المقطعية ( Panel Data) تصنف نماذج السلاسل الزمنية المقطعية(Panel data) كأحد أهم الاساليب القياسية

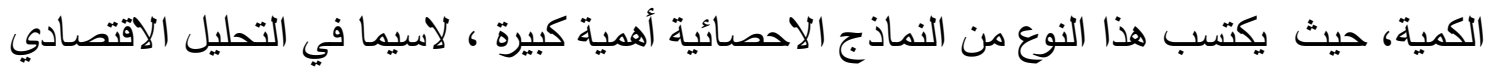

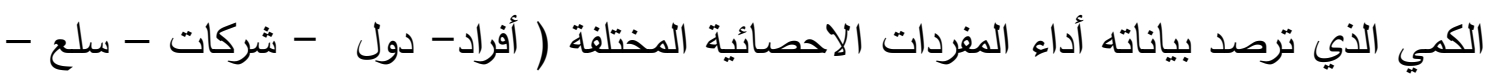

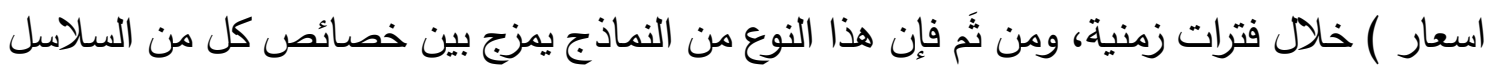


الزمنية Time series، التى تصف سلوك مفردة واحدة خلال فترة من الزمن، وخصائص البيانات المقطعية Cross section التى تصف سلوك عدة مفردات مستقلة خلال نقطة زمنية

محددة) Gujarati, 2012)

وتكمن أهمية استخدام السلاسل الزمنية المقطعية مقارنة بكل من نماذج السلاسل الزمنية ونماذج البيانات المقطعية فيما يلى:

- تأخذ بيانات السلاسل الزمنية المقطعية في الاعتبار عدم تجانس المفردات (تباين) heterogeneity

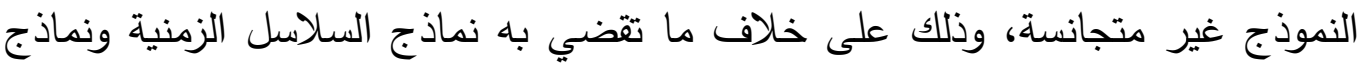

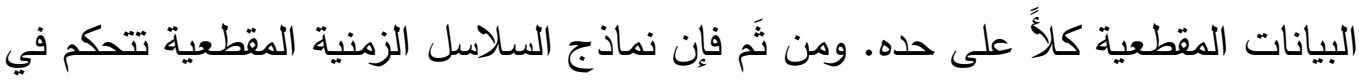
تحيز المقدرات.

- طبيعة ذللك النوع من النماذج يُنتج بدوره معلومات أكثر مقارنة بنماذج السلاسل الزمنية

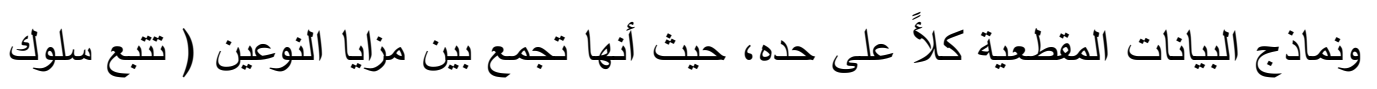

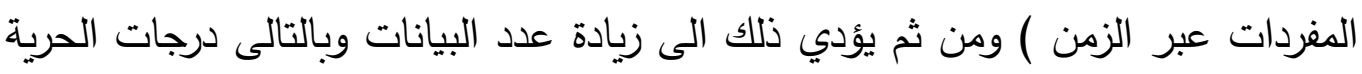
مما ينعكس إيجابيا على كفاءة التحليل الإحصائي.

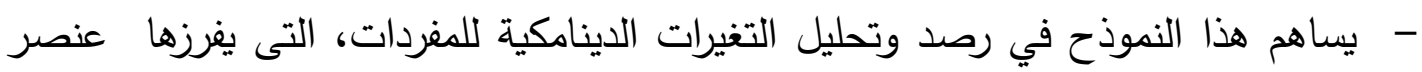
الزمن وتأثيره على سلوك عدة مفردات مقطعية.

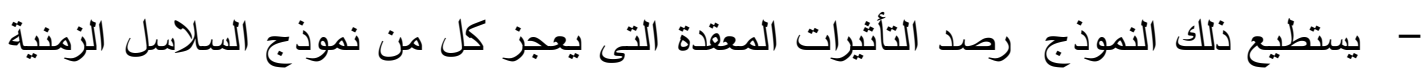

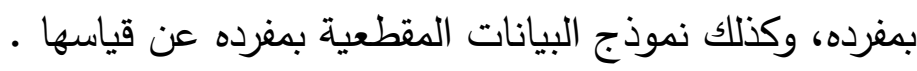

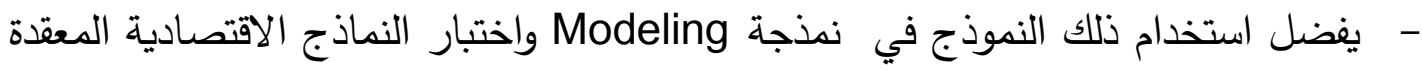
بطريقة أكثر دقة، فعلى سبيل المثال تحليل آداء أو سلوك المفردات الاقتصادية ( مؤسسات

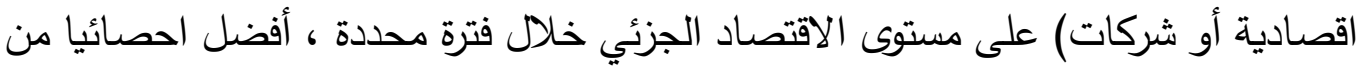

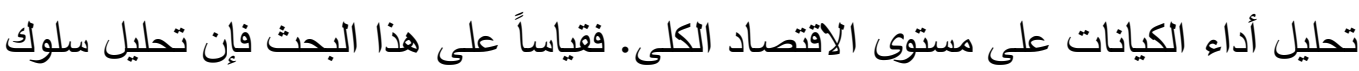

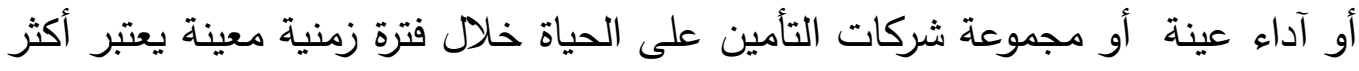

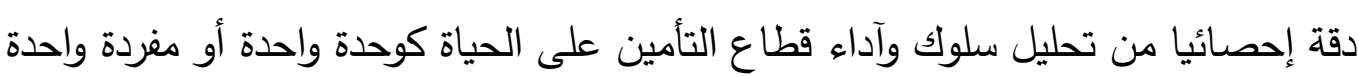

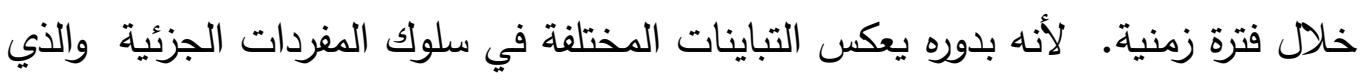


يتلاشي بطبيعة الحال عند تحليل قطاع التأمين على الحياة كوحدة واحدة ومن ثم لا يمكن رصده أو اختباره بمستوى دقة مقبول إحصائيا (Baltag, 2005) ثانياً تقدير نماذج السلاسل الزمنية المقطعية

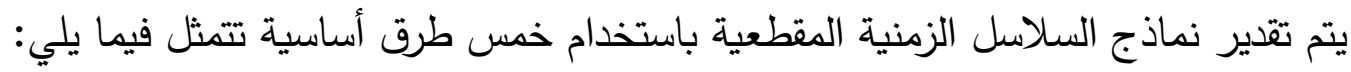
1) أسلوب السلاسل الزمنية الفردية حيث يتم تقدير معاملات الانحدار لكل مفردة من مفردات الدراسة بصورة فردية خلال فترة

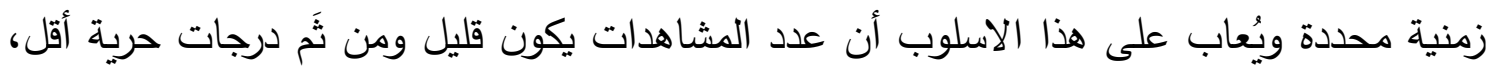

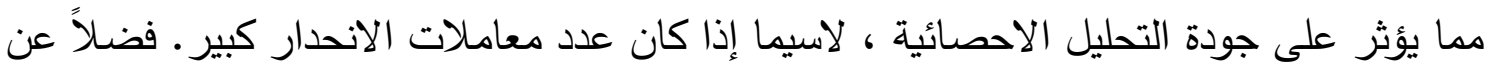
ذللك فإن هذا الاسلوب يتجاهل المعلومات المستمدة من المفردات الآخرى التى تعمل في ذات الات البيئة

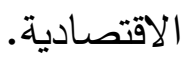

$$
\text { 2) اسلوب البيانات المقطعية }
$$

حيث يتم استخدام المربعات الصغرى الاعتيادية Ordinary Least Squares لتقدير نموذج الانحدار لجميع المفردات عند نقطة زمنية محددة، وبالرغم أنه قد يكون عدد المشاهدات كبير

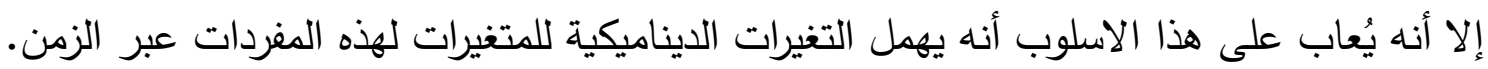

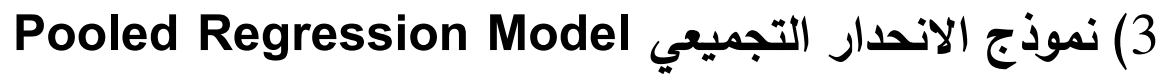

ويُطلق على هذا النموذج أيضاً "نموذج المعاملات الثابتة" حيث يتجاهل هذا النموذج كلأ

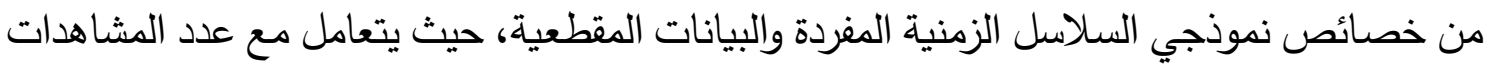
( عدد النقاط الزمنية Xدد المفردات) كأنها تخص مفردة واحدة وبالتالي فإن معاملات الانحدار ثابتة لا تتغير لا وفقاً لخصائص كل مغردة على حده ولا وفقا للسنوات المختلفة.

4ixed Effects Model نموذج التأثيرات الثابتة يتعامل هذا النموذج أيضاً مع عدد المشاهدات (عدد النقاط الزمنية ×عدد المفردات) ولكنه يتميز عن النموذج التجميعي بأنه يسمح بتحليل سلوك المفردات منفردة من خلال إدارج معاملات متغيرات صورية ثابتة تعبر عن كل مفردة على حده. 5andom Effects Model نموذج التأثيرات العشوائية 
يتعامل هذا النموذج أيضاً مع عدد المشاهدات (عدد النقاط الزمنية ×عدد المفردات) ولكنه

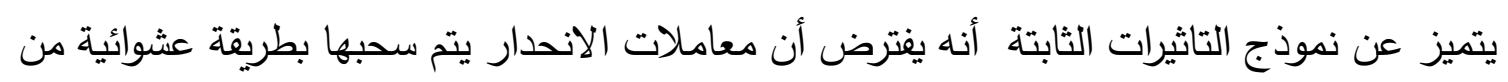

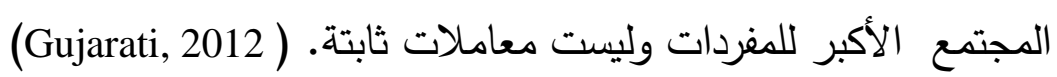

\section{ثالثاً النماذج المستخدمة في الاراسة}

تقتصر الدراسة على استخدام ثلاثة نماذج فقط؛ النموذج التجميعي، و نموذج التاثيرات الثابتة ، ونموذج التأثيرات العشوائية، حيث يتم تقدير معاملات هذه النماذج و اختبار معنوياتها الإحصائية

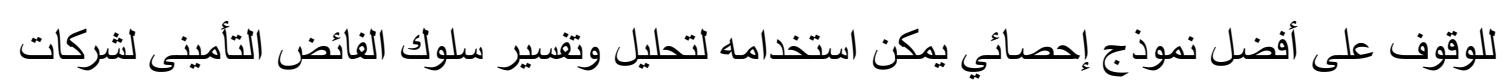

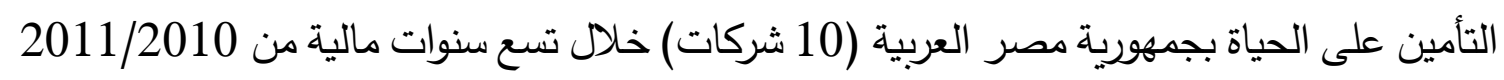
حتى 2019/2018 فضلاً عن استخدام هذا النموذج في التنبؤ بسلوك الفائض التأمينى. متغيرات الدراسة

تثمل الدراسة الإحصائية المتغير التابع (y) والذى يتمثل في فائض أو عجز النشاط

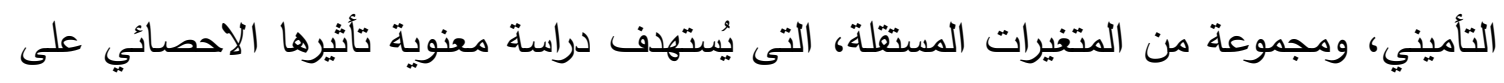

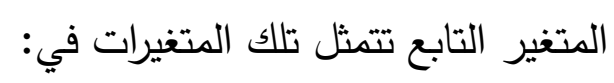

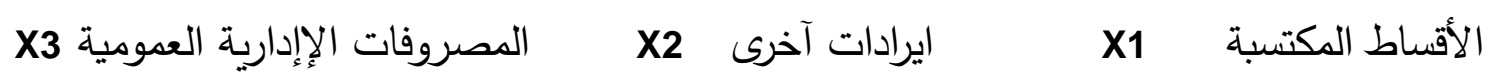

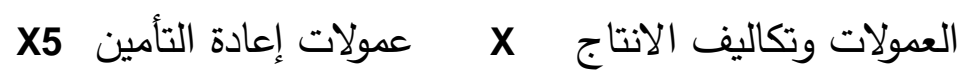

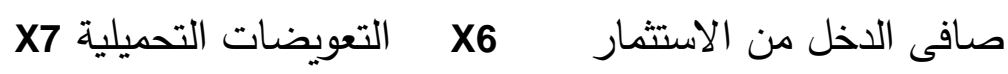

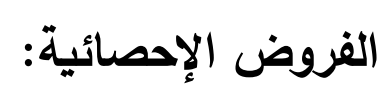
تأخذ الفروض الإحصائية: الإحية، التي سوف يتم اختبارها باستخدام نماذج بيانات السلاسل الزمنية

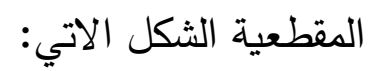
H0 : يوجد تأثير لأي متغير من المتغيرات المستقلة على المتغير التابع أو بمعنى آخر جميع

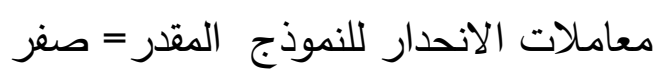

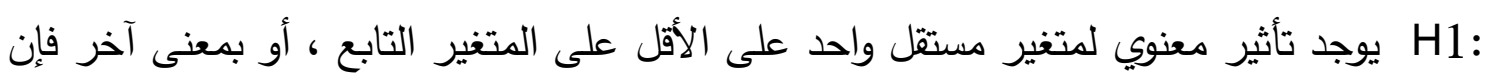

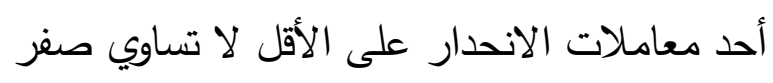




\section{التقدير باستخدام النموذج التجميعي (نموذج الاراسة الأمثل)}

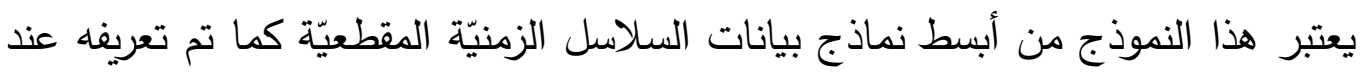

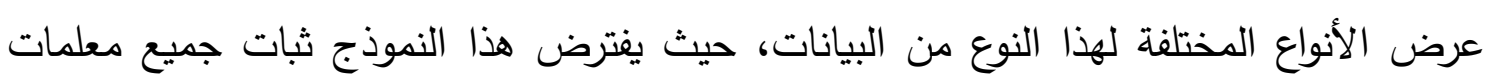
النموذج عبر الزمن، بافتراض أنّ تأثير الزمن ثابت، يقوم هذا النموذج بتقدير معلمات النيات المتغيّرات

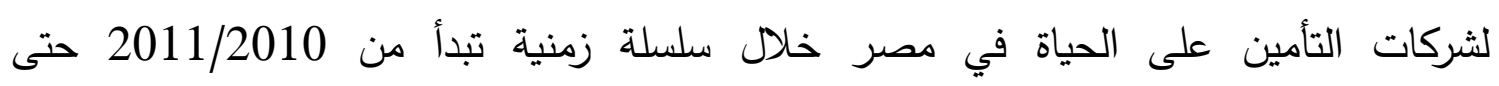

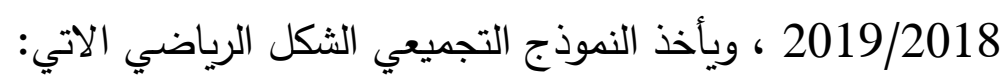

$$
Y_{i t}=\beta_{0}+\sum_{j=1}^{k} \beta_{j} X_{j i t}+\varepsilon_{i t}, \quad i=1,2, \ldots n, \quad t=1,2, \ldots, T
$$

$$
\text { حيث أن: }
$$

t المشاهدات الخاصة بالمتغير التابع للثركة i في الفترة الزمنية :

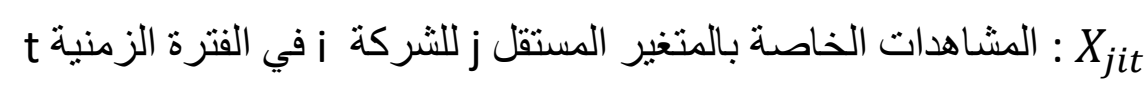

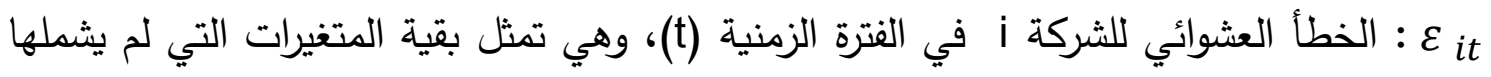
النموذج و التي تتغير من شركة الى آخرى عبر الزمن. [E( ، ويكون تباين حد الخطأ العشوائي ثابت [ن الشركات (Individual effects) ثابتة ومحدة لكل المنشآت، ويمكن استخدام طريقة المربعات الصغرى الاعتياديّة في تقدير معلمات هذا النموذج. تقدير النموذج التجميعي يشتمل جدول (3) على نتائج تقدير أثر متغيرات الدراسة المستقلة على فائض أو عجز

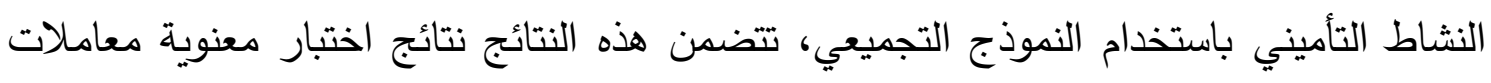

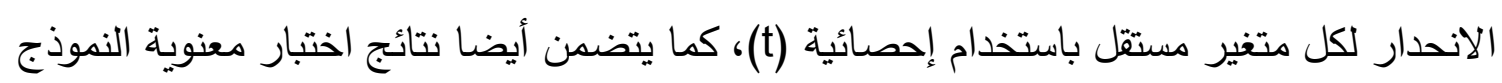

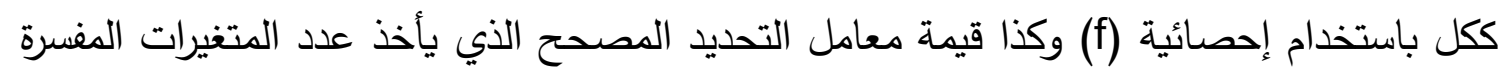
في الاعتبار Adjusted R2, ، التي تعكس جودة النموذج المتمثلة في نسبة مساهمة المتغيرات 
المستقل في تفسير سلوك أو تباين المتغير التابع. كما يتم استخدام مستوى معنوية 5\% لاختبار معنوية معاملات الانحدار ومعنوية النموذج المقدر .

جدول (3)

نتائج تقدير أثر متغيرات الاراسة المستقلة على فائض أو عجز النشاط التأميني باستخدام النموذج التجميعي

\begin{tabular}{|c|c|c|c|c|}
\hline المتغيرات المستقلة & معاملات الانحدار & الخطأ المعياري & t-Statistic & Prob. \\
\hline ثابت النموذج & -4279.469 & 15904.97 & -0.269065 & 0.7887 \\
\hline الأققساط المكتسبة & 0.446655 & 0.130440 & 3.424212 & 0.0010 \\
\hline إيرادات أخرى & 0.897358 & 0.503184 & 1.783359 & 0.0788 \\
\hline المصروفات الادارية العمومية & -0.700483 & 0.549615 & -1.274496 & 0.2066 \\
\hline العمولات وتكاليف الإنتاج & -0.302210 & 0.304620 & -0.992087 & 0.3245 \\
\hline عمولات إعادة التأمين & 2.053264 & 1.770379 & 1.159788 & 0.2500 \\
\hline صافي الدخل من الاستثمار & 0.221484 & 0.108020 & 2.050406 & 0.0440 \\
\hline التعويضات التحميلية & -0.181407 & 0.100055 & -1.813064 & 0.0740 \\
\hline R-squared & \multicolumn{4}{|c|}{0.734545} \\
\hline Adjusted R-squared & \multicolumn{4}{|c|}{0.708374} \\
\hline F-statistic & \multirow{2}{*}{\multicolumn{4}{|c|}{$\begin{array}{l}28.06652 \\
0.000000\end{array}$}} \\
\hline Prob (F-statistic) & & & & \\
\hline
\end{tabular}

المصدر : إعداد الباحث باستخدام برنامج

في ضوء نتائج جدول (3) يتضح أنه يوجد متغيران مستقلان (الأقساط المكتسبة و صافى بأنى

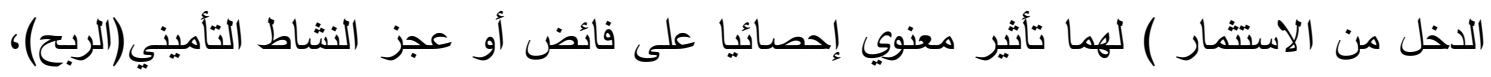

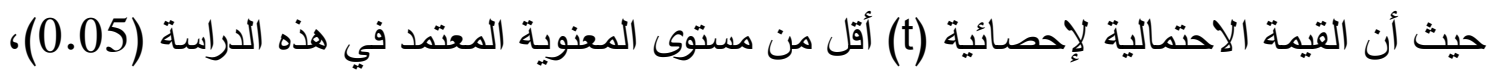
مما يعنى رفض الفرض العدم القاض بعدم معنوية هذه المتغيرات المفسرة.

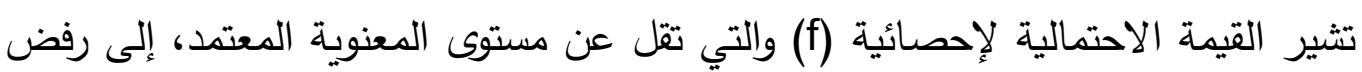
الفرض العدم القاض بعدم معنوية النموذج التجميعي، كما يتضح من خلال قيمة معامل التحديد 
المصحح أن المتغيرات المفسرة بالنموذج تساهم بنحو 73\% من التغيرات الحادثة في المتغير التابع أو بمعنى أخر فائض النشاط التأميني وفقا للدراسة الحالية.

$$
\text { توصلت الدراسة إلى بعض النتائج كانت من أهمها ما يأتى: }
$$

1- يعتبر سوق التأمين على الحياة المصرى من الاسواق الواعدة ، حيث بلغت نسبة اقساط لهاط

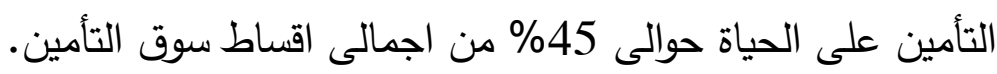

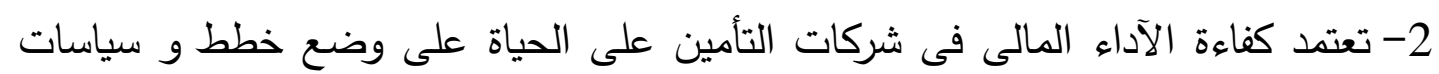
رشيدة للاكتتاب والاستثمار ونجاح هذه الخطط.

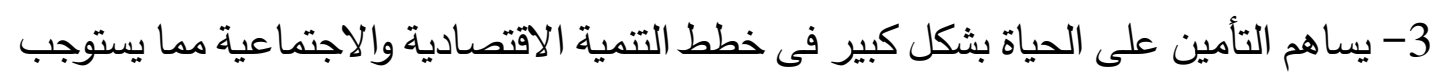
معه درجه عالية من الكفاءة المالية للشركات التى تمارسه. 4- تحقق بعض شركات التأمين على الحياة التجارى عجزاً فى ناتج النشاط التأمينى خلال معظم الماته فترة الدراسة مما يدل على وجود قصور فى السياسات الاكتتباية والاستثمارية لتلك الثركات، والتى قد يكون أحد أسبابها ارتفاع معدلات التكلفة الكلية.

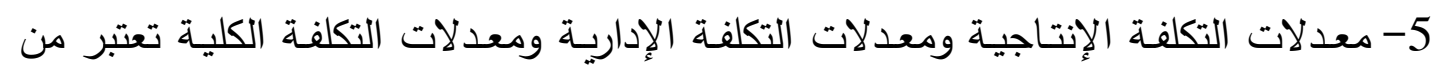

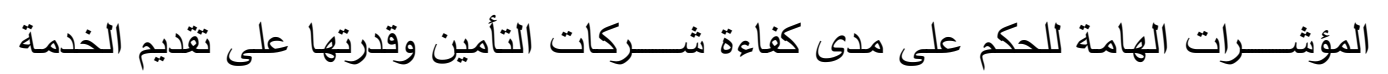

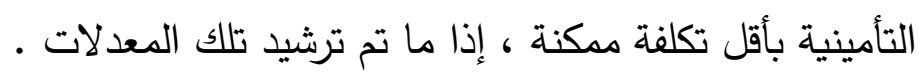

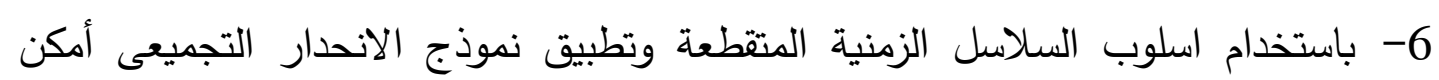
التوصل إلى نموذج خاص بشركات التأمين على الحياة التجارى حيث يأخذ فى اعتباره

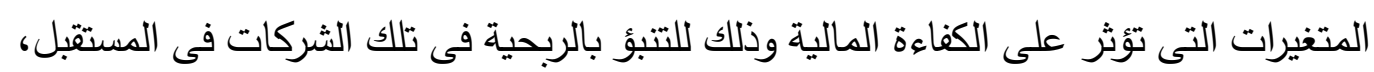

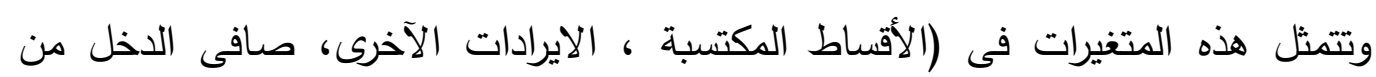

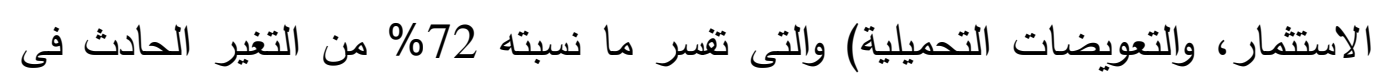
المتغير التابع وهو الربحية والتى تعبر عن الكفاءة المالية.

التوصيات 


$$
\text { توصى الباحثة بالآتى: - البئ }
$$

1- أهمية مرجعة السياسات الاكتتابية والاستثمارية لشركات التأمين على الحياة نظرا لأهميتها

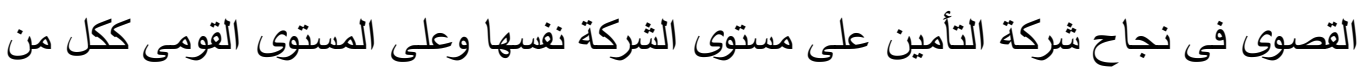
حيث مساهتها فى تمويل خطط التمية الاقتصادية والاجتماعية.

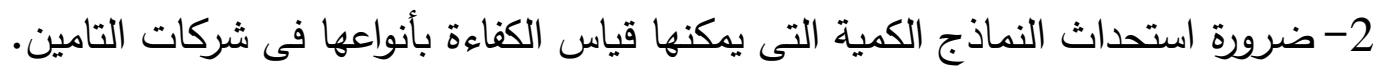

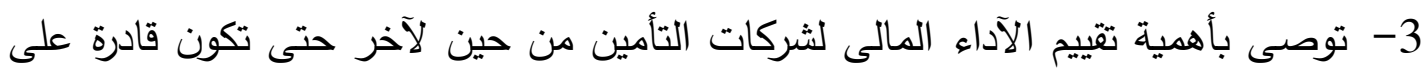

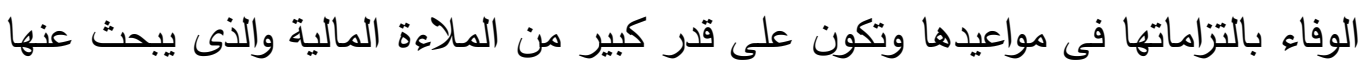
العملاء وحملة الوثائق

\section{أولاً المراجع العربية}

1) أبو بكر ، عيد أحمد(2010). "تطوير التحليل المالي بالأساليب الكمية للتنبؤ بالأزمات المالية

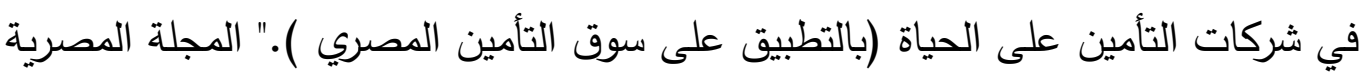

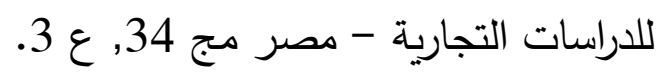

2) حسين، محمد وحيد عبدالباري (1994). "نموذج كمي مقترح لترشيد القرار الاستثماري لأموال التأمينات العامة بشركات التأمين التجاري بجمهورية مصر العربية".المجلة المصرية الثردية

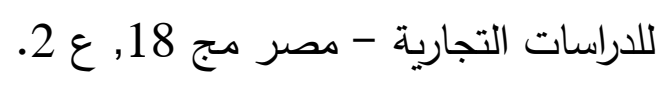

3) أبو بكر ، عيد أحمد(2006). "نموذج كمي لمحددات الكفاءة المالية في التأمين على الحياة:

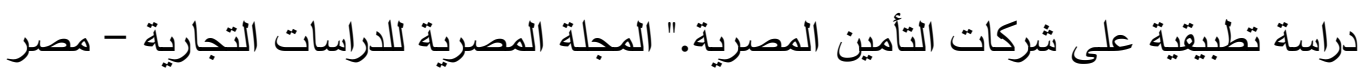

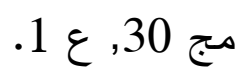

4) البحبوحى، عفاف سليمان ( 2001)" دراسة تحليلية إحصائية مقارنة لسوق تأمينات الحياة

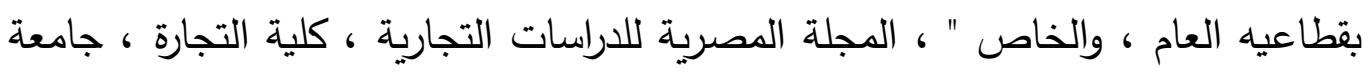

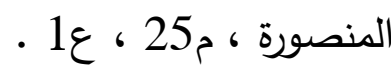

5) أبو بكر ، عيد أحمد(2004). "'" تحليل إحصائى مقارن لمعدلات تحميلات قسط التأمين على المي الحياة فى السوق المصرى".مجلة الدراسات المالية والتجارية - مصر .

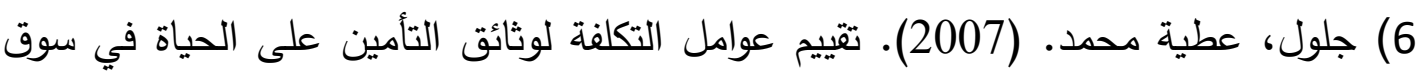

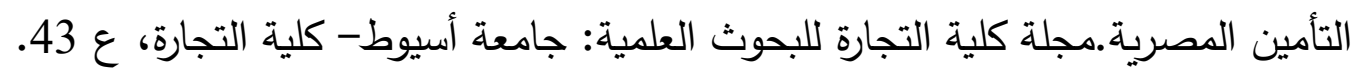


7) أبو بكر، عيد أحد، عبد البارى، طارق عزت(2010). " تحديد العوامل المؤثرة على ناتج

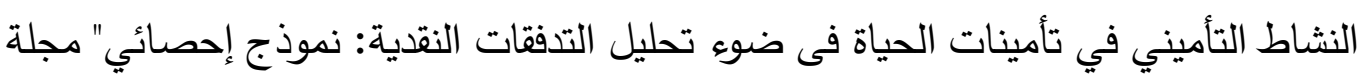

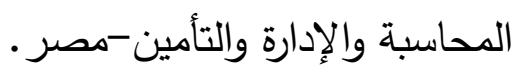

8) أبو بكر، عيد أحمد(2013)."تطبيق معايير تقييم الاداء المالى على شركات التأمين على التى

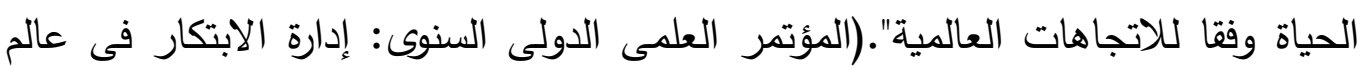

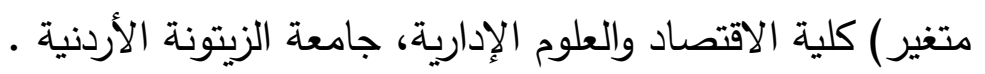
9) الهيئة العامة للرقابة المالية ,الكتاب الاحصائى عن نشاط سوق التأمين ,أعداد مختلفة.

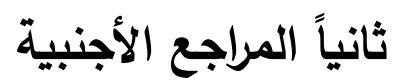

10) Mahmoud, O. H. (2008). A multivariate model for predicting the efficiency of financial performance for property and liability Egyptian Insurance Companies. Applying Multivariate Statistical Models, 53.

11) Almajali, A. Y., Alamro, S. A., \& Al-Soub, Y. Z. (2012). Factors affecting the financial performance of Jordanian insurance companies listed at Amman Stock Exchange. Journal of Management research, 4(2), 266.

12) Akotey, J. O., Sackey, F. G., Amoah, L., \& Manso, R. F. (2013). The financial performance of life insurance companies in Ghana. The Journal of Risk Finance.

13) Derbali, A., \& Jamel, L. (2018). Determinants of performance of Tunisia insurance companies: Case of life insurance. International Journal of Productivity and Quality Management, 24(4), 531-542.

14) Gujarati, D (2012). Econometrics by example. Macmillan. 